\title{
Thriving with water: Developments in amphibious architecture in North America
}

\author{
Elizabeth English ${ }^{1, a}$, Natasha Klink ${ }^{1}$ and Scott Turner $^{1}$ \\ ${ }^{1}$ School of Architecture, University of Waterloo, 7 Melville St S, Cambridge, Ontario, Canada
}

\begin{abstract}
There is increasing awareness worldwide that traditional flood-mitigation strategies that attempt to control the flow of water only increase the likelihood of catastrophic consequences in the long run, when failure inevitably occurs after years of complacency and development behind flood barriers. Amphibious architecture is a non-defensive flood mitigation and climate change adaptation strategy that works in synchrony with a floodprone region's natural cycles of flooding, allowing water to flow rather than creating an obstruction. Since the height to which an amphibious building rises is not necessarily fixed but adapts to the variable depth of flood water, amphibiation can accommodate rising sea levels and land subsidence as well. Amphibious retrofitting can provide measurable cost savings compared to other flood mitigation strategies, performing well in loss avoidance studies for both flood and wind damage. An amphibious approach to planning and construction recognizes the beneficial aspects of seasonal and occasional flooding, allowing us not merely to live with water, but to thrive with it. This paper reviews case studies of both existing and proposed amphibious buildings, with discussion of their systems and components. It also discusses the limitations of amphibious construction, some of the regulatory obstacles that have discouraged its development, and possible paths forward. The first International Conference on Amphibious Architecture, Design and Engineering, ICAADE 2015, was held in Bangkok, Thailand, in August 2015. The second, ICAADE 2017, will convene at the University of Waterloo in Canada in June 2017.
\end{abstract}

Keywords: amphibious architecture, flood mitigation, disaster resilience, climate change adaptation, buoyant foundation, amphibious retrofit

\section{Flooding and the Built Environment}

As global climate change causes sea levels to rise and weather events to become more extreme, the occurrence of severe floods will become more commonplace around the world. The large populations living in deltaic or riverine floodplain regions will in particular be severely affected, especially those living at the lowest levels of income.

Historically, populations have settled in areas with ready access to water - not only to quench thirst, but for food production, defensibility, transport, and more moderate temperatures. The establishment of human settlements on the floodplains adjacent to rivers is commonplace. The soil in floodplains is typically highly fertile due to nutrients in the sediment deposited by receding flood water. This pattern of settlement presents challenges as global climate change fosters rising sea levels and more frequent and severe weather even.

Today, $40 \%$ of the world's population inhabits areas vulnerable to sea level rise, and $20 \%$ live in riverine basins at risk of increasingly frequent flooding [1,2].
In the last 20 years, the 10 worst floods around the world have displaced over 1.1 billion people and resulted in damages of over US\$165 billion [3]. Governments and organizations worldwide are becoming increasingly aware that traditional flood mitigation strategies that alter the environment, such as levee- and dike-building, often increase the long-term likelihood of catastrophic consequences when eventual failure occurs.

Current popular approaches to flood risk reduction promote the control of flooding by erecting barriers that may provide some measure of protection for the time being. But this temporary relief will be at the expense of future generations who, when the barrier system eventually fails, will bear the burden of devastation and difficult recovery. The greater the scope of flood control infrastructure, and the confidence it fosters in the communities it is designed to protect, the more disastrous the consequences are likely to be when an unanticipated failure occurs. New Orleans found itself in this devastating situation in 2005, suffering grave consequences when $80 \%$ of the city flooded due to compound failures of the levee system in the aftermath of Hurricane Katrina (Fig. 1) [4].

${ }^{a}$ Corresponding author: english@ecenglish.ca 
In the USA, one of the government-promoted strategies for protecting buildings in flood-prone areas is permanent static elevation. This term refers to retrofit construction in which buildings are elevated on vertical structural supports to a height above the projected 100year flood level, i.e., putting a building "up on stilts". However, climate change is causing severe and unexpected weather patterns and unprecedented flood depths. When flooding exceeds the height to which a statically elevated house is raised, the protection this strategy was designed to provide becomes ineffectual, resulting in water damage to the building and displacement of the occupants it was intended to protect. Climate adaptation and hazard mitigation strategies require a greater degree of adaptability, which calls for the development of new housing types and retrofit techniques that build resilience in populated regions where flooding is expected to increase. Amphibious construction offers an innovative response to these challenges as a proactive adaptation strategy that mitigates flood damage and allows people to return to their homes and communities shortly after a flood recedes.

\section{What is Amphibious Architecture?}

Amphibious architecture refers to an alternative flood mitigation strategy that allows an otherwise-ordinary structure to float on the surface of rising floodwater rather than succumb to inundation. An amphibious foundation retains a home's connection to the ground by resting firmly on the earth under usual circumstances, yet it allows a house to float as high as necessary when flooding occurs. A buoyancy system beneath the house displaces water to provide flotation as needed, and a vertical guidance system allows the rising and falling house to return to exactly the same place upon descent. Amphibious architecture is a flood mitigation strategy that works in synchrony with a floodprone region's natural cycles of flooding, rather than attempting to obstruct them.

Amphibious construction may also refer to one of several "hybrid" conditions. One such is where the weight of a structure is partially supported by both land and water simultaneously, i.e., where gravity loads are shared by a buoyant substructure and structural elements bearing directly on the solid ground below the water. Another situation is where a mechanical system such as jacks or hydraulic pumps is used to elevate the structure temporarily. A third condition is a "wetproofing" strategy, whereby residents occupy the first floor during dry seasons and move to an upper storey during periods of flooding.

Amphibious design also includes the concepts of land use planning, site selection, policy considerations and community resilience issues such as the place of amphibious buildings in multiple-lines-of-defense systems. Amphibious engineering addresses issues such as infrastructure, mechanical systems and utilities, system components and selection criteria, and codification and certification concerns [5].

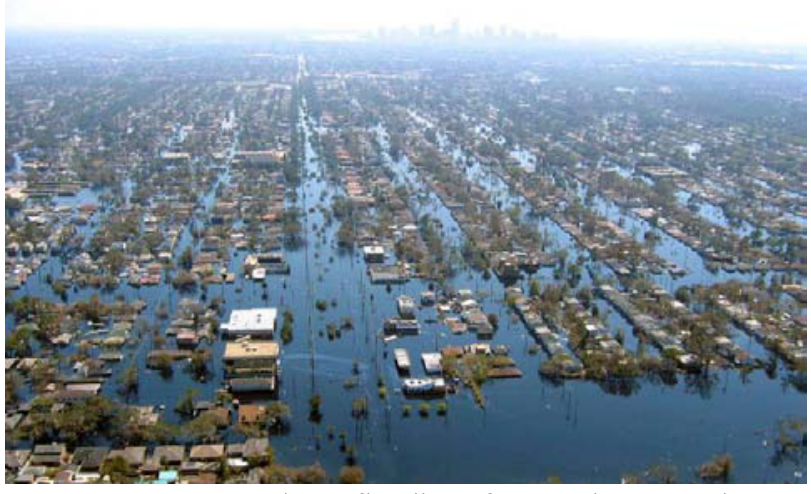

Figure 1. New Orleans flooding after Hurricane Katrina (photo courtesy of NOAA)

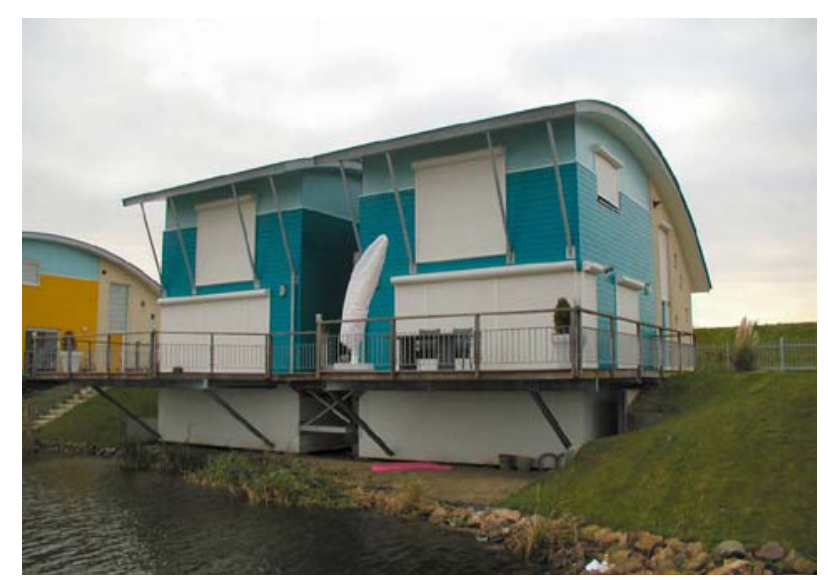

Figure 2. Amphibious housing in Maasbommel by Dura Vermeer and Factor Architecten (photo by Hans van Beek)

In environmentally sensitive locations, amphibious construction "lives with" the flooding, using the floodwater itself as the active agent to elevate a building. Rather than creating barriers, amphibious strategies accept the presence of floodwater but prevent it from causing significant damage to the building. Since the height to which an amphibious building rises is not fixed, but accommodates the depth of the rising water, amphibious structures easily adapt to rising sea levels and land subsidence. The system acts passively, requiring no further preparations during a flood event, although evacuation is recommended.

Amphibious construction is not a new concept: for over forty years, residents of Old River Landing, Louisiana, have been retrofitting their fishing camps with expanded polystyrene (EPS) buoyancy blocks and sliding sleeves fitted around steel guidance posts embedded in the ground. This configuration allows the houses to rise with the floodwater, mitigating the damage caused by the seasonal flooding of the nearby Mississippi River [6]. In the last two decades, the Netherlands has built amphibious housing along the Maas River, which has a long history of severe flooding (Fig. 2).

Actor Brad Pitt launched the Make It Right (MIR) Foundation in 2007, with the goal of giving to former residents of the Lower Ninth Ward in New Orleans 150 affordable, sustainable and hurricane-resistant new homes. Morphosis Architects designed an amphibious house for MIR, called the FLOAT House and completed 
in October 2009 (Fig. 3). The base of the house is a "chassis" formed of EPS encased in fiberglass-reinforced concrete. The vertical guidance posts are inside, one at each end of the house.

Other amphibious prototypes have been built in the UK, Bangladesh, the United States and Thailand, and new projects are under development in France and Canada. Most recent examples of amphibious buildings around the world are found in new construction where they predominantly serve moderate- to high-income populations in industrialized countries. However, amphibious architecture has much to offer to rural and low-income populations in developing countries as well, either by inclusion in new low-cost housing projects or as a retrofit solution to increase resilience in flood-prone regions. Our work focuses on developing retrofit amphibious applications for existing houses in vulnerable communities.

\section{Advantages of Amphibiation Over Elevation}

\subsection{Performance During Flood Events}

Unlike houses elevated to a fixed level (Fig. 4), amphibious houses can easily accommodate varying levels of floodwater. A house with permanent static elevation (PSE) will be damaged when the depth of flooding exceeds the height to which it is elevated, while amphibious homes are able to adapt to variable flood levels by rising as the water rises (Fig. 5). The long-term degradation of protection that affects PSE due to soil subsidence and rising sea levels is alleviated by an amphibious building's ability to maintain an elevation that is always above the surface of the water. The vertical guidance posts (VGPs) may easily be extended if increases in flood depths are predicted.

\subsection{Social Benefits}

Compared to static elevation, amphibious systems are less disruptive to residents' everyday lives. Buildings with permanent static elevation remove their occupants from street level, requiring long flights of stairs or the expense of installing an elevator. This presents an ongoing inconvenience to residents as well as creating a significant impediment for the elderly and others with impaired mobility. Amphibious buildings, conversely, are only slightly elevated off the ground to accommodate buoyancy elements, thereby enabling a greater degree of accessibility. Aesthetically, statically elevated houses may produce significant voids at street level (Fig. 6), whereas amphibious houses help preserve the original character of a neighborhood (Fig. 7).

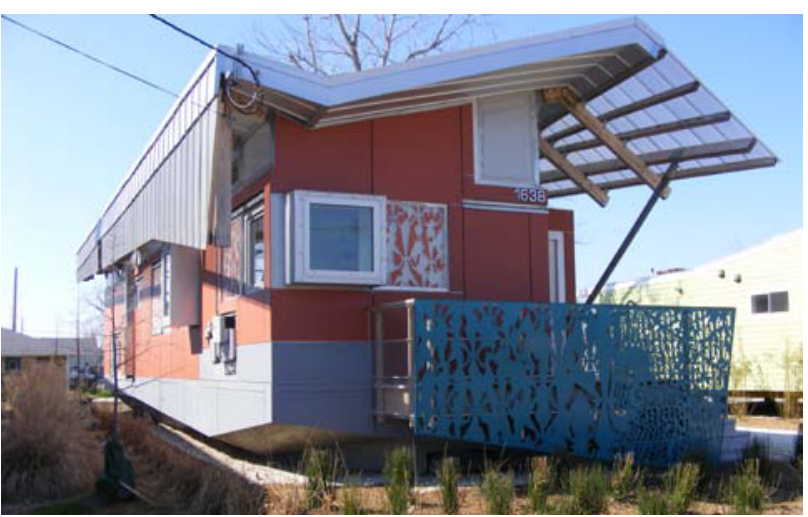

Figure 3. FLOAT House, New Orleans (photo courtesy of Morphosis Architects)

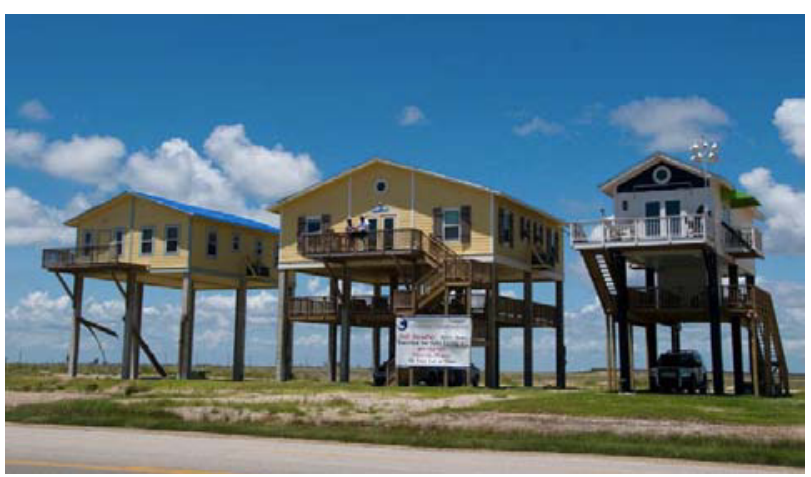

Figure 4. Statically elevated houses in Galveston, Texas, USA (photo courtesy of FEMA)

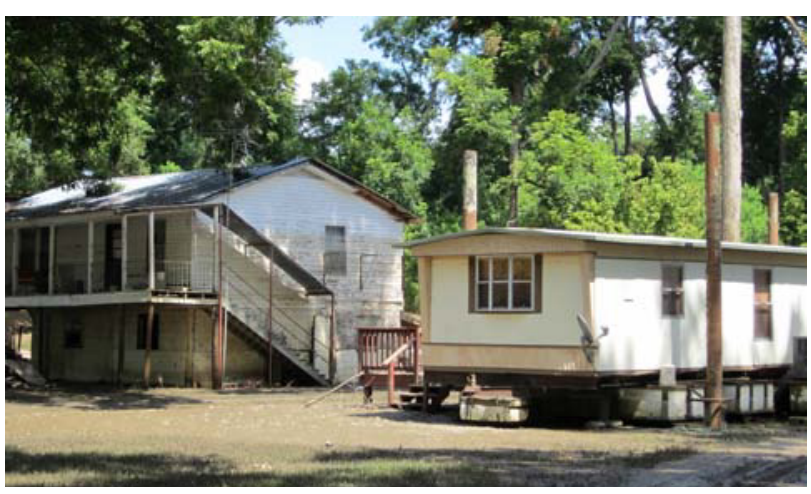

Figure 5. A static home (left) and an amphibious home (right) in Old River Landing, Louisiana; note waterline on static house marking depth of flooding (photo by E C English)

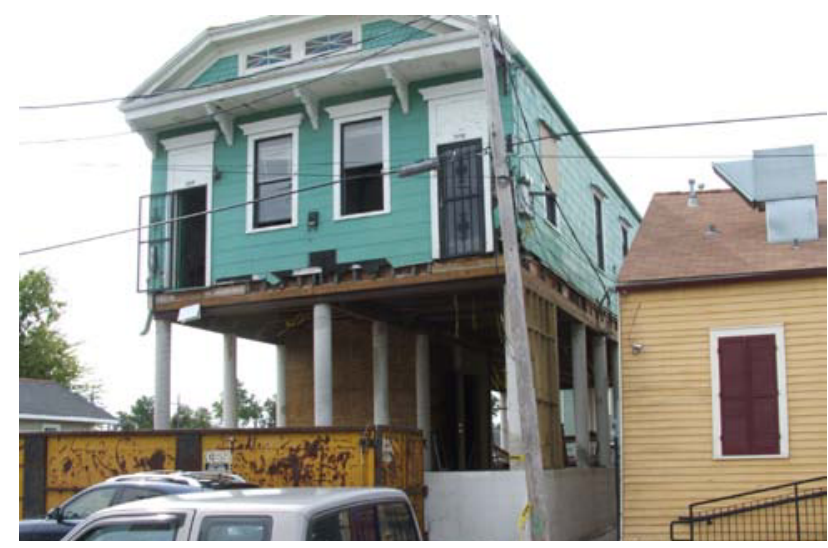

Figure 6. In New Orleans, permanent static elevation disrupts a neighborhood's coherence and changes its character (photo by E C English) 


\subsection{Economic Benefits}

Amphibious construction also offers economic benefits compared to ordinary construction. In new construction, an amphibious system represents an additional cost over conventional construction due to the need for a more elaborate foundation system (either a water-tight box on a slab or a water-tight box within an open outer box). As a percentage of the total cost of new construction, this represents an additional 5 to 10 percent, but it provides a means to avoid the much greater costs associated with flood damage.

Amphibious retrofitting offers considerable cost savings in comparison to permanent static elevation. This is because PSE requires the replacement of the entire foundation system, whereas an amphibious retrofit retains the existing foundation, merely supplementing its ongoing gravity load-bearing function with systems to provide vertical guidance to resist lateral loads and buoyancy to provide uplift. Detailed cost comparisons show that amphibious retrofits on average range from $1 / 3$ to $1 / 2$ of the cost of PSE.

In severe flood events, houses with amphibious retrofits are subject to less damage than those with no flood mitigation strategy or even those with PSE (Fig. 8). The cost savings vary on a case-by-case basis, but amphibious construction generally offers significant benefit when compared to alternatives. This topic is discussed further in Section 6 below, "Avoiding the Costs of Damage".

\section{Impediments to the Use of Amphibious Construction}

Although amphibious construction is a vernacular approach that has traditionally been used in flood-prone rural areas in such countries as Thailand, Cambodia and Iraq, the construction of new, fully-engineered and codecompliant amphibious buildings is a relatively recent phenomenon. Such buildings may now be found in the Netherlands, the UK, Thailand and the United States, and a new amphibious house is currently nearing the start of construction in Nova Scotia, Canada. Support for the concept is increasing in North America, although government resistance has stalled approval processes in the United States. The US Federal Emergency Management Agency (FEMA) prioritizes the relocation of residents away from vulnerable areas, and withholds flood insurance through the National Flood Insurance Program (NFIP) from would-be homeowners wishing to build new amphibious houses on the technical consideration that the houses are not "adequately anchored to prevent flotation" [7]. Municipalities are threatened with removal of their good standing with the NFIP were they to issue building permits for new amphibious construction. Such NFIP approval is crucial for would-be homeowners, since US banks require flood insurance as a precondition for providing mortgages for homes in flood zones.

However, in rural Old River Landing, Louisiana, a remote recreational camping and fishing community

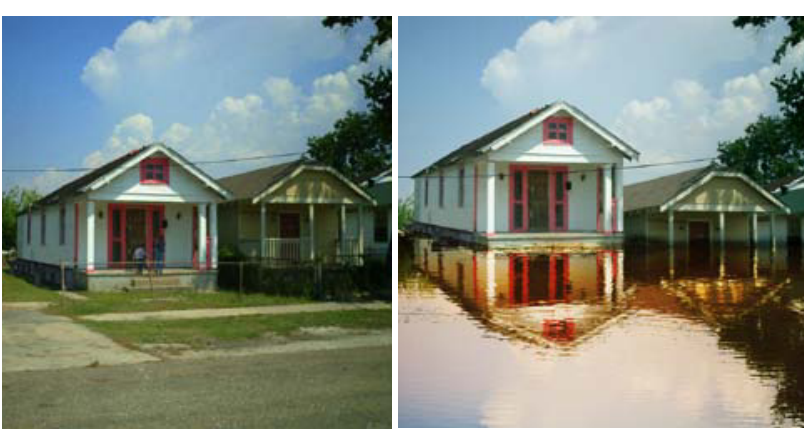

Figure 7. Amphibiation provides flood protection without significantly changing the building's appearance (photo by E C English, renders by BFP)

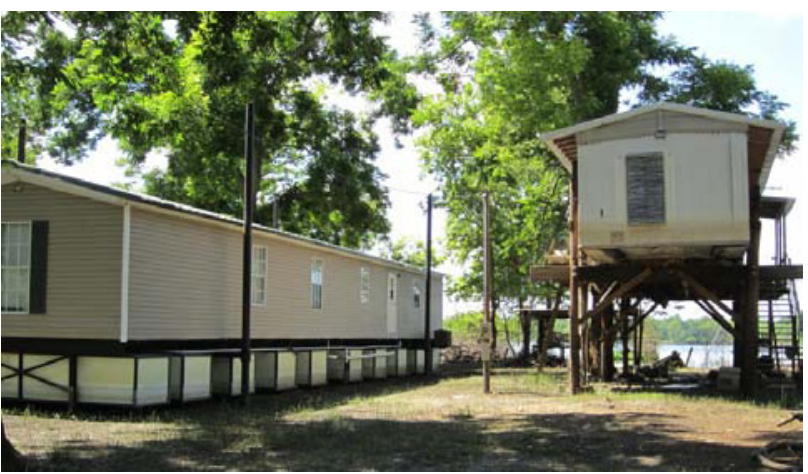

Figure 8. An amphibious home and one with PSE in Old River Landing, Louisiana, after flooding in spring 2011; note waterline on elevated house on right (photo by E C English)

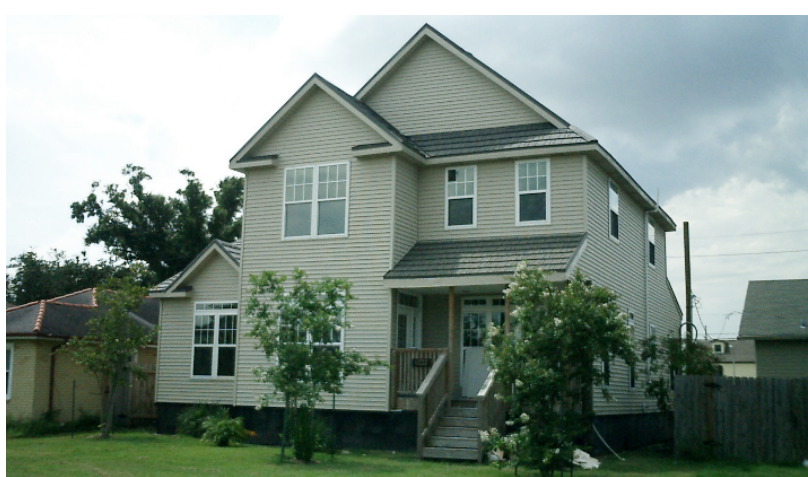

Figure 9. Lakeview House, New Orleans (photo by E C English)

outside the Mississippi River levee system on the banks of a lake called Raccourci Old River, there is a collection of mostly do-it-yourself amphibious houses that has been developing over the last forty years. The restaurant and bait shop in the community was amphibiated in 2002 after several occurrences of particularly high floods. Some of these structures have now been functioning reliably for as long as four decades, without the need for NFIP insurance because they no longer experience flood damage (see Figs. 5, 8).

The Lakeview House in New Orleans (Fig. 9), completed in 2007 as an amphibious house, was built by a developer on speculation. The house was originally supported directly on two hollow steel barge sections resting on a concrete slab-on-grade. Because the developer was unable to obtain FEMA approval for NFIP insurance for this amphibious house in a special flood hazard zone, he was unable to sell the house. Eventually, after the house sat empty for five years, he converted the 
foundation to a conventional pier-and-beam system so that new owners would not be barred from eligibility for NFIP insurance and thus from obtaining a mortgage [8].

FEMA has since (as of June 2014) agreed to allow amphibious retrofit construction for existing homes (although still without eligibility for NFIP), but the restrictions on new amphibious construction in the United States still remain in force.

\section{The Buoyant Foundation Project}

The Buoyant Foundation Project, (BFP) established in 2006 by Prof. Elizabeth English and former students at the Louisiana State University (LSU) Hurricane Center, was originally founded to support New Orleans' recovery in the wake of Hurricane Katrina [5]. It is a registered non-profit organization in the State of Louisiana. Since its inception, the BFP has expanded its mission to include the design of amphibious solutions for both retrofit and new construction applications, with a focus on retrofit strategies for vulnerable low-income communities in flood-prone areas around the world. The BFP has now also established a research group at the University of Waterloo at its School of Architecture in Cambridge, Ontario.

A buoyant foundation is a particular type of amphibious foundation, specifically designed to be retrofitted to an existing house that is already slightly elevated off the ground and supported on short piers. It allows a house to remain close to the ground and retain its original appearance under normal circumstances, but to rise with the water and float on its surface when flooding occurs, then settle back into its original position as the water recedes. In flood-prone regions a buoyant foundation reduces a house's vulnerability to flood damage and, with wider implementation, increases the long-term resilience of its surrounding community.

With the use of buoyancy blocks, a structural subframe and vertical guidance posts, buoyant foundations work much like floating docks, allowing a building to float up and down but not move horizontally. Underneath the house, the buoyancy blocks displace water to provide flotation. Vertical guidance posts (VGPs) restrain lateral movement so that the building can only move straight up and down. A structural sub-frame reinforces the existing floor framing, supports the buoyancy blocks and connects the house to the VGPs. Utility lines may be fitted with long, coiled "umbilical" lines for water and electrical supply, and self-sealing "breakaway" connections that disconnect sewer and natural gas lines when the house begins to rise (Fig. 10) [6].

A fully-engineered buoyant foundation system can provide flood mitigation that is both more effective and considerably less expensive than other current options. A community's vulnerability both to relatively mild, seasonal flooding and to severe, otherwise-catastrophic flooding can be dramatically reduced by implementing this low environmental impact strategy. Buoyant foundations are not, however, a universal solution, as they are not currently designed to accommodate the lateral forces of high-velocity flow or the impact of

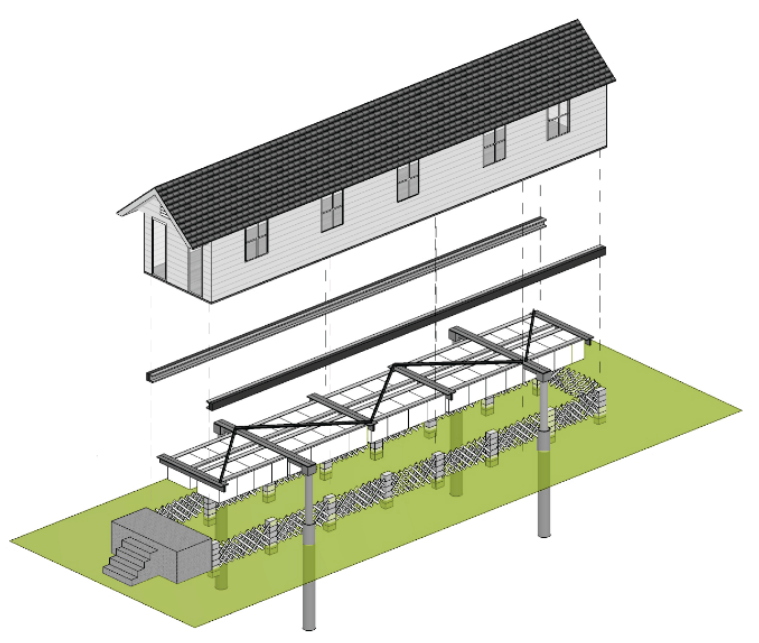

Figure 10. Exploded axonometric drawing of the BFP system (drawing by BFP)

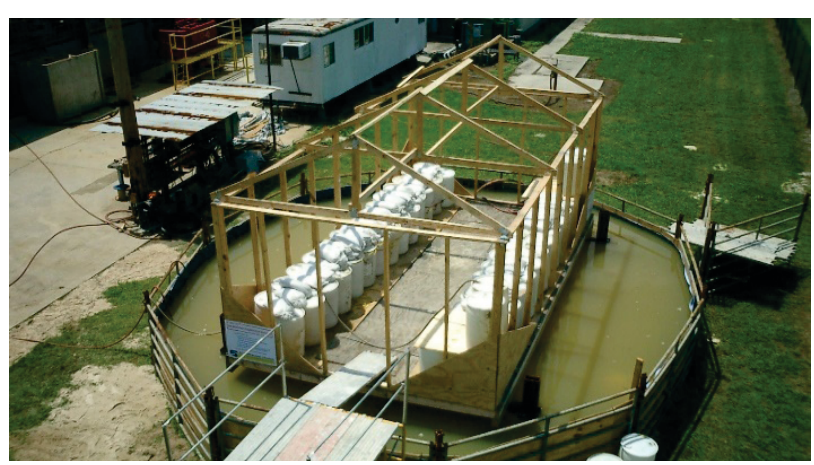

Figure 11. LSU BFP prototype (photo by Jill Bambury)

sizeable waves.

The BFP has proposed buoyant foundation designs for communities in Bangladesh, Nicaragua and Jamaica, and research has been conducted to investigate amphibious retrofits as a viable solution for indigenous communities in the United States and Canada. Further projects are under development for Galveston, Texas; Cow Bay, Nova Scotia; and Stinson Beach, California.

\subsection{Louisiana State University (LSU) Prototype}

In 2007, our team of LSU Hurricane Center faculty and students successfully constructed and tested a fullscale prototype buoyant foundation system installed on a platform structure representing the full width $(4 \mathrm{~m})$ and $40 \%(7.3 \mathrm{~m})$ of the full length (approx. 18m) of a standard shotgun house, a common building typology in south Louisiana (Fig. 11) [6]. This testing established the effective performance of the buoyant foundation system under a variety of conditions. The results indicate that buoyant foundation systems can be adapted as a proactive strategy for flood mitigation to a broad range of situations world-wide.

\subsection{The LIFT House, Bangladesh}

The LIFT House pilot project was constructed on the grounds of the Housing and Building Research Institute in Dhaka, Bangladesh in 2011 (Fig. 12). Designed by 
Prithula Prosun as her Master of Architecture thesis at the University of Waterloo, this two-family amphibious housing prototype proposes a unique approach to infrastructure in developing regions: the house itself is self-sustaining and independent of the city's infrastructural systems.

The house provides all essential services to its residents, including water collection, filtration and reuse, solar electricity, and composting toilets. Built as an experimental prototype, the two housing units have different systems for achieving buoyancy. The first unit's foundation consists of a rectangular reinforced concrete box, open at the top and positioned below grade, similar to the method used in the amphibious houses in Maasbommel, the Netherlands (as shown in Fig. 2). The buoyancy system for the second unit is truly innovative: the house is supported on a bamboo frame, which is then filled with bundles of recapped, recycled empty plastic water bottles. Eight thousand air-filled bottles displace enough water to lift the house and its occupants during flood conditions (Fig. 13) [9].

\subsection{Casa Anfibia, Nicaragua}

Nicaragua is experiencing social and environmental crises, placing residents in chronically flooded communities under threat of displacement. Casa Anfibia is an amphibious housing design proposal for the riverine community of Malacatoya that would allow its residents to remain in their homes during and after flood events (Fig. 14). It could provide for them an opportunity to break out of the repetitive cycle of relocation and rebuilding that currently plagues their lives. This solution might become an example for implementation in other low-income communities as well.

The design features renewable and recycled materials, is highly transferable to different contexts, and provides affordable, flood-protected living space for the residents, along with a surrounding deck for their pigs and chickens. Efforts at resettlement instituted by NGOs and the Nicaraguan government have not succeeded; ecorefugees have a high rate of return, often to substandard living conditions. The proposed adaptation strategy allows this population to remain on their lands of origin.

The design utilizes recycled plastic barrels for buoyancy due to their widespread availability and low cost. Bamboo is used to construct the house itself, as it combines low weight with a carbon footprint that is $35 \%$ lower than concrete block [10]. It is also a local, renewable resource that can be regrown quickly, reducing local deforestation.

This project was not completed due to the dissolution of our Nicaraguan partner organization, but many of the concepts that were developed have been adapted for the Jamaican retrofits described in the next section [11].

\subsection{Port Maria and Bliss Pastures, Jamaica}

Field research in Jamaica was conducted to investigate communities at risk of inland flooding with the goal of designing buoyant foundation retrofits for

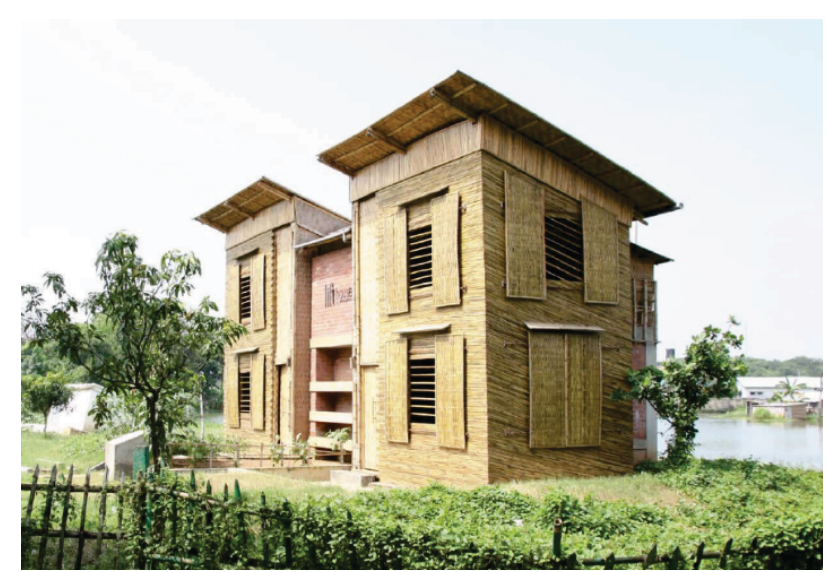

Figure 12. LIFT House, Dhaka, Bangladesh (photo courtesy of Prithula Prosun)

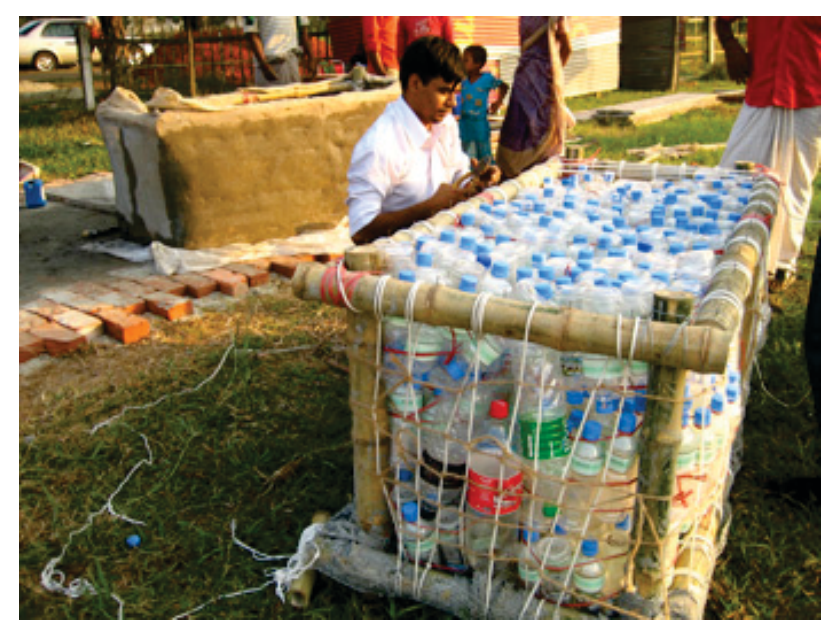

Figure 13. LIFT House buoyancy blocks using recapped plastic bottles (photo courtesy of Prithula Prosun)

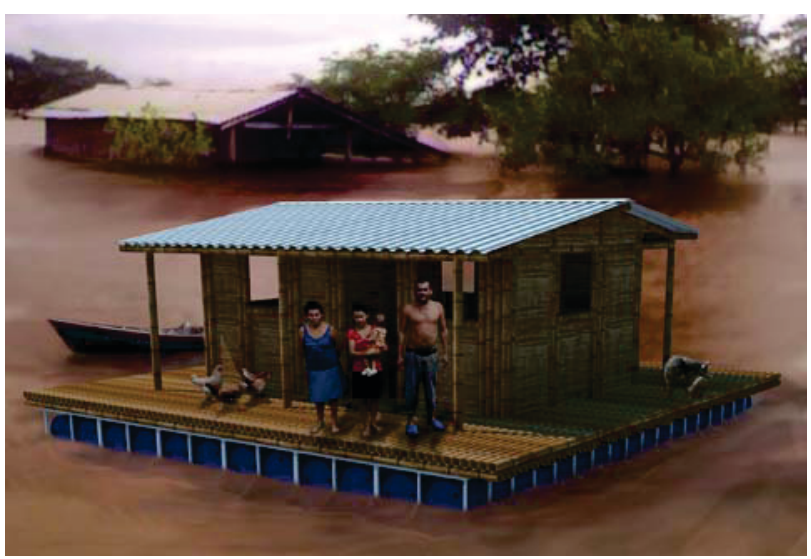

Figure 14. Casa Anfibia proposal, Malacatoya, Nicaragua (render by $B F P$ )

houses in flood-vulnerable locations. Two communities that satisfied the necessary criteria were identified: Port Maria in Saint Mary Parish and Bliss Pastures in Trelawny Parish.

The city of Port Maria is located along the Outram River, with many houses sited directly adjacent to the river and at high risk of flooding. The very poor neighborhood we visited floods nearly every time there is heavy rainfall, and it can flood even without rainfall when the ground is supersaturated and the river levels are high. In addition to causing property damage and the 
displacement of residents, flood events also present serious public health issues. Flooding causes pit latrines to overflow, leading to serious health hazards such as ringworm and fungal infections. These problems can linger long after the actual flood event, from which the water generally recedes within a day or two. The soil can remain saturated for months and the humid conditions greatly extend the time required for houses to dry, with lasting damage such as mold and fungus infestations [11].

Bliss Pastures is located near Wakefield and has had two major floods in the past 25 years, with the most recent occurring in 2009. When flooding occurs, residents must relocate, often for up to 6 weeks at a time.

A buoyant foundation retrofit for a house in each of the Port Maria and Bliss Pastures communities has been designed and detailed (Fig. 15). They will demonstrate a low-cost, replicable strategy for community resilience in the face of flood events that otherwise seriously disrupt the lives of these residents living in poverty.

Utilizing cost-effective, locally available materials and local construction practices was a primary consideration in developing the buoyant foundation retrofit designs for the selected houses. The assembly consists of several elements: there are buoyancy blocks composed of expanded polystyrene below the existing floor structure, and a plywood structural substrate that reinforces the existing structure and provides support for the buoyancy blocks. There is also a vertical guidance system that uses low-cost, readily available timber telephone poles to prevent any lateral movement of the house as it rises, floats and descends (Fig. 16).

To ensure that the existing structures have adequate strength to carry the new forces associated with buoyancy, the floor framing structures are reinforced by attaching strips of water-resistant plywood oriented perpendicular to the floor joists. The perpendicular orientation provides stiffness and also enables the distribution of the uplift forces from the buoyancy blocks.

The initial retrofit design used sealed, recycled 5gallon cooking oil jugs to provide buoyancy. The jugs themselves were a simple and inexpensive source of buoyancy; however, the materials and labor required to make the wire mesh "cages" to contain the jugs and attach them underneath the house were found to be prohibitively expensive. In the final design these were replaced with expanded polystyrene (EPS) when research determined that EPS would be significantly less expensive than recycled jugs after the cost of labor was factored in, as the use of EPS would allow a significant simplification of the construction process. This resulted in an estimated $65 \%$ reduction in the cost of the buoyancy elements. Furthermore, the ecological benefits of using recycled jugs would have been greatly diminished by the need to encase them in steel wire cages.

Construction costs of the amphibious retrofits, which include both labour and materials, are estimated at $\$ 3,765$ USD $\left(\$ 93.81 / \mathrm{m}^{2}\right)$ for the Port Maria house and $\$ 2,414$ USD $\left(\$ 90.24 / \mathrm{m}^{2}\right)$ for the Bliss Pastures house. If the labor is donated, the cost is reduced to $\$ 2,064$ USD

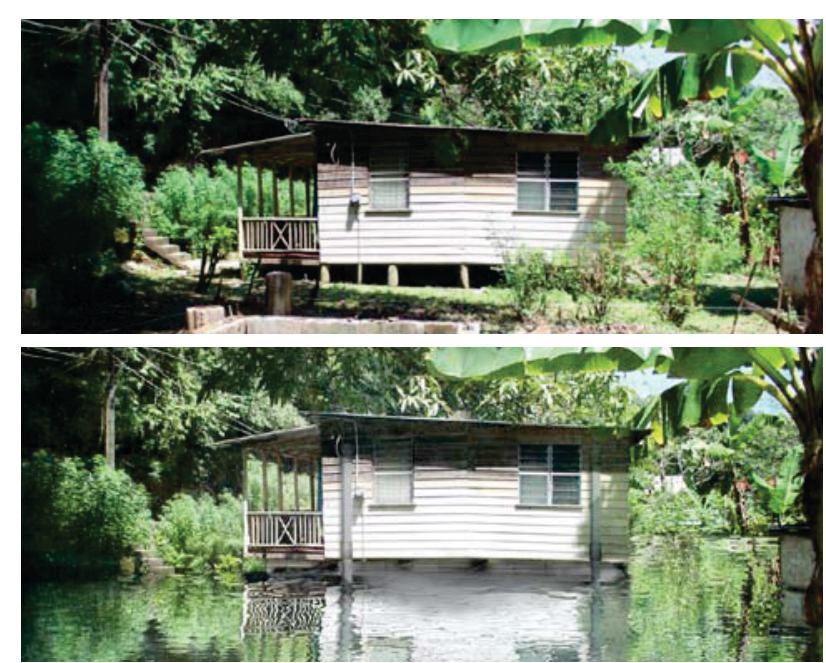

Figure 15. Port Maria house (above) and render of Port Maria retrofit floating in flood conditions (below) (images by $B F P$ )

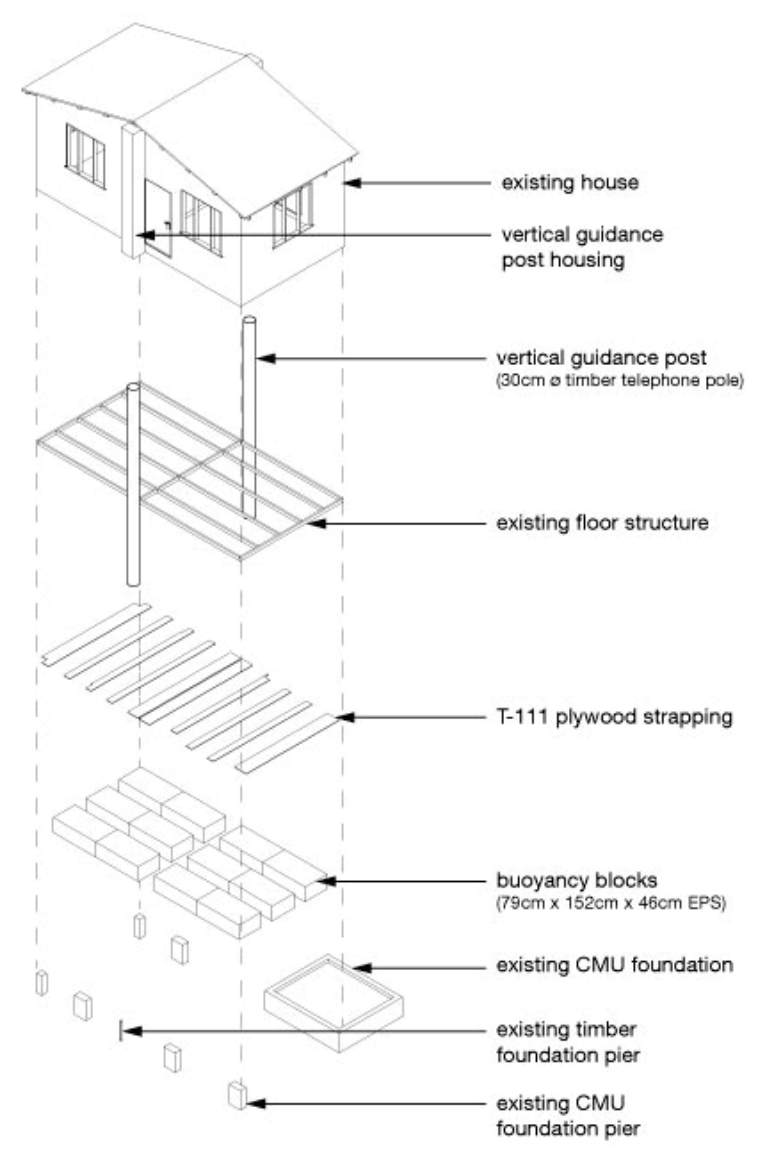

Figure 16. Exploded axonometric of Bliss Pastures retrofit (drawing by $B F P$ )

for the Port Maria house and \$1,199 USD for the Bliss Pastures house, illustrating that buoyant foundation retrofits can be affordable for people of limited means. When compared to the potential costs of relocating and repairing flood damage, buoyant foundation retrofits are a low-cost, low-environmental impact solution. Enabling residents to remain in their undamaged homes eliminates the necessity of constructing new housing for those displaced by flooding. 


\subsection{Isle de Jean Charles, Louisiana}

The Native American Biloxi-Chitimacha-Choctaw Band of Isle de Jean Charles, Louisiana, is rapidly losing their traditional homeland. Their dwindling community lives on low-lying land that is shrinking as it is progressively submerged by rising sea levels and land subsidence due to extensive sub-surface oil and gas extraction. Cultural ties to the land and a lack of resources to relocate as a community leave the remaining band members vulnerable to an ever-growing risk of flooding. Nineteen of the band's twenty-six residences remaining on the island are already permanently elevated; the proposed solution targets the remaining seven low-lying structures.

The island is inadequately protected by its ring levee system and is positioned outside of an authorized new levee alignment (Fig. 17). This combination of factors threatens to overwhelm the island, its houses, and its remaining inhabitants.

Retrofitting these homes with amphibious foundations would enable them to float safely when flooding occurs. The intent of our project was to provide a safe and cost-effective strategy to enable the at-risk members of the Isle de Jean Charles community to remain in their homes until a suitable long-term solution could be found.

In January, 2016, the US Department of Housing and Urban Development announced the awarding of grants to assist vulnerable communities in adapting to climate change [12]. The Biloxi-Chitimacha-Choctaw Band received $\$ 48$ million of this funding to relocate their community, making them the US's first climate refugees.

\subsection{Leeville, Louisiana}

Leeville is a small town located in LaFourche Parish in south Louisiana, just outside of the levees along Bayou LaFourche. It lies on a narrow strip of land between Port Fourchon, the largest oil port in the US, and Golden Meadow, the first town within the levee system. The area suffers from high rates of subsidence and erosion, which when combined with sea level rise, create a situation of pervasive land loss. Moreover, with the recent reconstruction and elevation of Louisiana Highway 1, which used to pass through Leeville to connect Golden Meadow to Port Fourchon, the roadway has been rerouted to bypass Leeville, which is now connected to the highway only by a ramp and thus is effectively isolated.

The residents of Leeville are mostly fishermen or workers in the oil industry. In the present scenario where their land is disappearing and flooding is ever more frequent, saving their homes has become a critical issue that needs an immediate solution. Buoyant foundation retrofits to existing housing would be an economical and effective way to provide a flood mitigation strategy for Leeville that would reduce vulnerability to flooding and enhance the resilience of the entire community (Fig. 18).

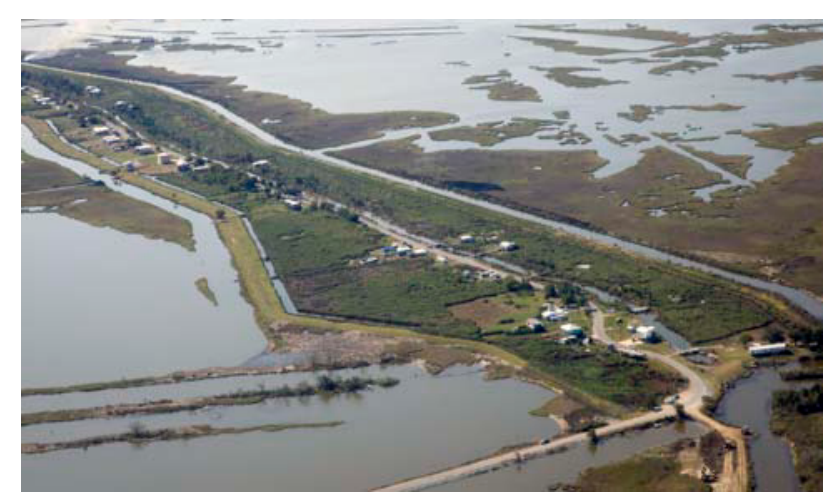

Figure 17. The narrow island of Isle de Jean Charles (photo by Terri Garland)
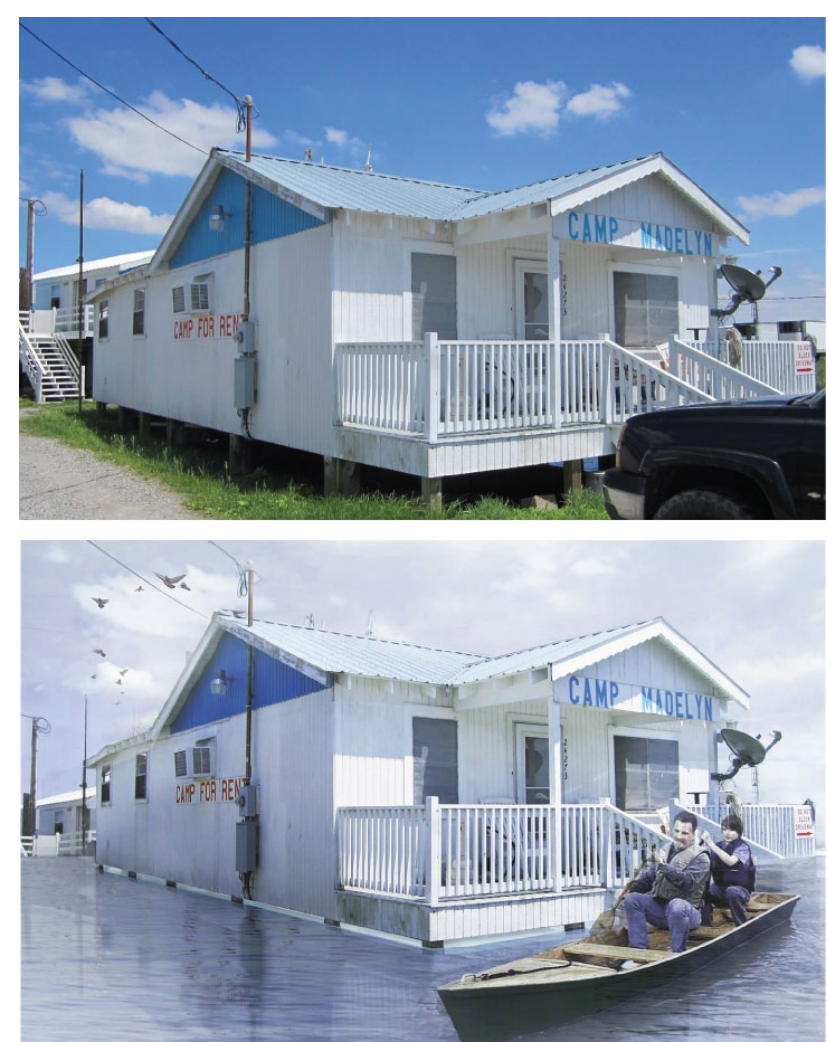

Figure 18. Camp Madelyn, Leeville, Louisiana, current condition and after amphibious retrofit (photo by E C English, render by BFP)

\subsection{Pinaymootang First Nation, Manitoba}

Central Manitoba is home to the Pinaymootang First Nation reserve, a traditional, tight-knit community of over 2000 members. It is part of the greater Interlake Reserves Tribal Council, and is located within the Lake Manitoba watershed along the Fairford River, which runs between Lake Manitoba and Lake St. Martin in the Canadian province of Manitoba. The community has strong connections to the land and the water, stemming from long-standing traditional beliefs and practices. While seasonal flooding is a natural occurrence in this region, its severity and irregularity have increased in recent years as a result of government-implemented water control infrastructures and procedures. These manipulations of the water flow rates, implemented for the benefit of urban areas that lie far beyond the reserves, 
have not only interfered with important cultural practices but also create serious threats to the community [13].

In June 2011, floods in Lake Manitoba, Lake Winnipeg, and Lake St. Martin displaced thousands of First Nations People living on four reserves north of Winnipeg: Pinaymootang, Lake St. Martin, Little Saskatchewan, and Dauphin River. This event left many buildings along the banks of Lake St. Martin damaged or destroyed (Fig. 19). Significant numbers of the band members living near Lake St. Martin were forced to evacuate, and have since lived in stressful conditions away from their homes and the support of their communities. Amphibious construction has the potential to provide these indigenous communities with a flood mitigation strategy that is simple, inexpensive to implement, and sensitive to their unique cultural needs.

New government housing to be provided to these communities will most likely be the modular housing commonly found on reserves across Manitoba and the rest of Canada (Fig. 20). This housing type is relatively straightforward to retrofit with a buoyant foundation, which could be designed as an easily replicable, modular kit-of-parts. The proposal of an amphibious retrofit strategy for the at-risk Interlake Reserves was wellreceived by the Pinaymootang community, as well as its Chief, Garnet Woodhouse, and the three Interlake Reserves Tribal Council members to whom it was proposed during a visit to the Pinaymootang reserve in January 2015 [14].

\subsection{Farnsworth House, Illinois}

Architect Ludwig Mies van der Rohe's Farnsworth House in Plano, Illinois, an internationally famous example of modernist domestic architecture, is an aesthetic culmination of simplicity, transparency, and integration with its surrounding landscape. Despite being originally designed in accordance with the projected 100year flood depth, it has sustained significant damage several times in recent years due to flooding of the adjacent Fox River (Fig. 21).

To address the increasing frequency and depth of flooding impacting the Farnsworth House, our competition project “ "Phibious Farnsworth" introduced an amphibious foundation system to raise and float the house in extreme flooding scenarios, and then lower it to its original height as the water receded, unobtrusively protecting this valuable cultural asset in a visually sensitive manner (Fig. 22).

The fully below-grade retrofit installation ensured that the outward design would remain visually unaltered. The project offered an effective alternative to the costly and time-consuming restorations that are required after each flood.

Our strategy replaced the house's conventional static concrete pylons with sleeves that would accommodate sliding vertical guidance posts. These posts, which would allow the house to rise and fall while restricting its lateral movement, were extensions of the house's existing wide flange columns, reaching 4-5 m below the surface of the ground. A steel subframe installed just below the ground

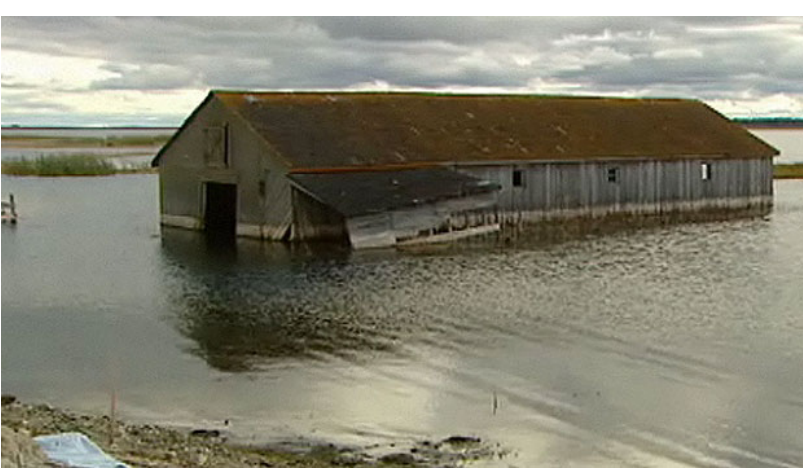

Figure 19. Flooding of Lake St. Martin, 2011 (image courtesy of $C B C$ )

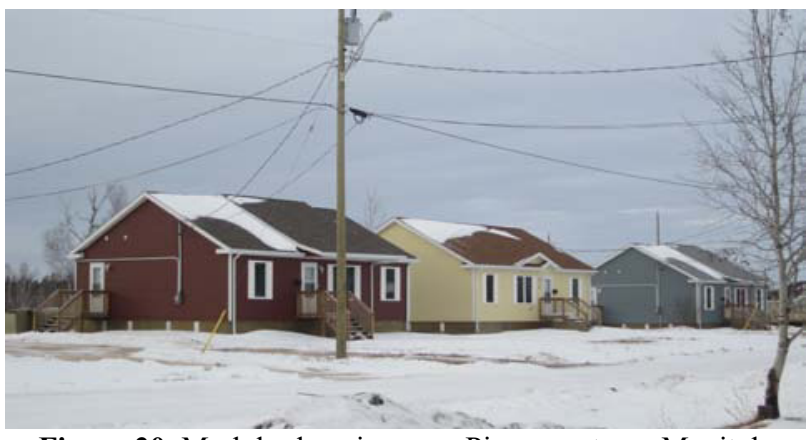

Figure 20. Modular housing near Pinaymootang, Manitoba (photo by E C English)

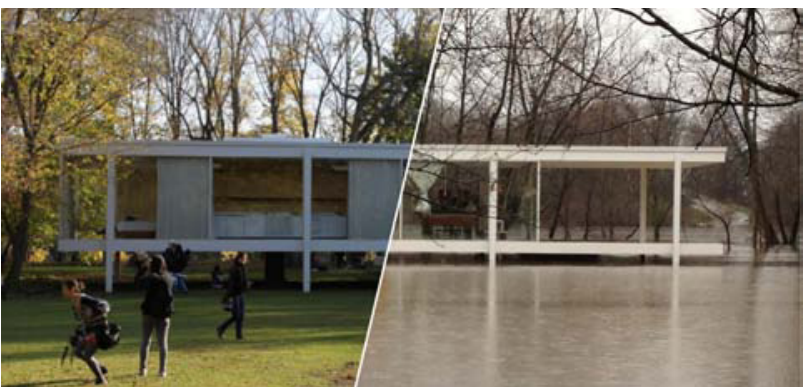

Figure 21. The Farnsworth House before and during flooding (photomontage by BFP)

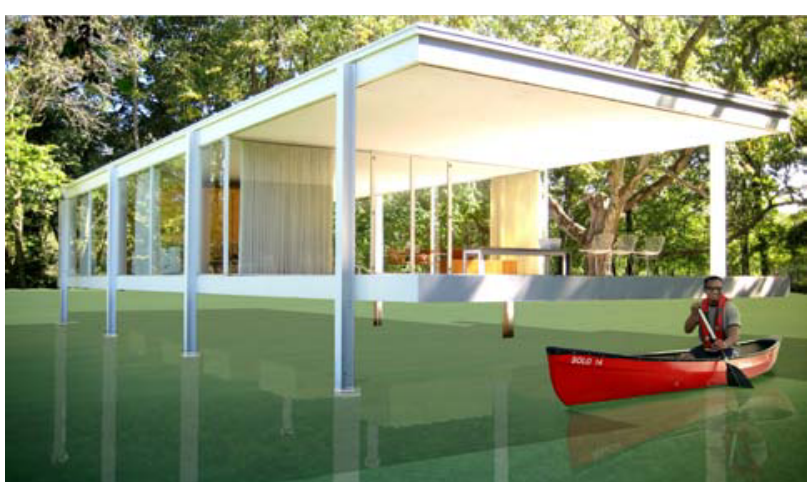

Figure 22. The Farnsworth House amphibiated (render by BFP)

surface would support a matrix of buoyancy blocks while remaining hidden from view. In the case of a flood, the buoyancy blocks would lift the house, with the subframe transferring the forces between the house, blocks and vertical guidance posts.

The 'Phibious Farnsworth entry to the 2014 Architizer A+ Awards design competition was selected as one of five Finalists in the Self-Initiated Projects category and received Honorable Mention in the Historic 
Preservation category. An amphibious retrofit can be designed to have minimal impact on the appearance of a structure; thus, amphibiation has enormous potential to provide visually appropriate protection from the impacts of global climate change for historically significant buildings.

\section{Avoiding the Costs of Damage}

\subsection{Loss Avoidance Studies}

Loss avoidance studies can quantify the cost advantages of a mitigation strategy by comparing the cost of implementing a flood mitigation system to the cost of damages incurred when a house is exposed to flooding without the proposed technology. This is calculated by combining three categories of losses: building repair costs, contents losses, and displacement costs [15]. Loss avoidance analyses performed for amphibious retrofits in two locations demonstrate the potential cost savings of adopting buoyant foundation retrofits as a flood mitigation strategy.

The Pre-Mitigation Flood Depth (PMFD) is the flood depth that would occur with the house in its current condition, which can be found by subtracting the height of the Finish Floor Elevation before mitigation (FFE) from the High Water Mark (taken from analyzing data of previous flood conditions). Typically, this is the depth of the water inside the house.

Building Repair Costs (BRC) use the Building Replacement Value (BRV) to calculate losses that occur through damage to structural, electrical, and mechanical components, in addition to drywall, cabinets and flooring. To calculate the total sum of BRC avoided by implementing a mitigation strategy that eliminates damage, the BRV, Square Footage and Flood Depth must be determined and then assessed using a Depth of Damage Calculation that determines the BRC.

Calculating the Contents Losses provides the costs of repairing damages that occurred to furniture, appliances, electronics, equipment, clothing, and power tools. To calculate losses incurred through damage to contents, the Contents Value (CV) of residents' material possessions is assumed to be $30 \%$ of the BRV.

Displacement costs refer to the funds required to cover living expenses while the occupants are displaced both during the flood event and also while repairs are being made, including rental expenses and meals. Displacement costs (DC) are based on the average household size and on the local per-diem rates for lodging and meals.

The Loss Avoidance Ratio (LAR) is an indicator of the cost savings associated with the adoption of a particular flood mitigation strategy, technique, or technology. It is calculated by estimating the costs likely to be sustained as a result of a flood, divided by the costs of the flood mitigation strategy implemented to prevent the losses. In simplest terms, it is the ratio between the costs associated with doing nothing and then paying for the damages and relocation costs after a flood event, versus the costs of implementing proactive flood mitigation measures.

If the LAR produces a value of above 1.0, the proposed flood mitigation strategy costs less than the damage and displacement from a single unmitigated flood event. Each successive flood event where damage would otherwise have occurred increases this ratio because the damage and relocation costs increase while the mitigation costs remain the same.

LAR can be expressed as a function of the total of the Building Repair Costs (BRC), Contents Losses (CL) and Displacement Costs (DC) calculated for the PreMitigation Flood Depth (PMFD), divided by the Cost of Flood Mitigation (CFM) as shown in Eqn. 1:

$$
\mathrm{LAR}=\frac{(\mathrm{BRC}+\mathrm{CL}+\mathrm{DC})_{P M F D}}{\mathrm{CFM}}
$$

A Loss Avoidance Study was conducted on a $101 \mathrm{~m}^{2}$ house in Leeville currently elevated off the ground $52 \mathrm{~cm}$ on average, with a Pre-Mitigation flood depth of $91 \mathrm{~cm}$. This study found an average loss avoidance ratio of 2.06-for every dollar (\$1.00) spent on flood mitigation through amphibious retrofits, two dollars and six cents (\$2.06) of repair and relocation costs were avoided. Bear in mind that these numbers represent the costs associated with one flood event. Subsequent flood events would increase this ratio, as new costs would be incurred by doing nothing while a onetime investment in amphibious flood mitigation strategies would continue to save money for the Leeville community [16].

A more detailed loss avoidance study was conducted for the Pinaymootang community. It examined the loss avoidance ratios for three different building replacement values and three different mitigation cost scenarios. This study found that the ratio of the cost of losses due to flooding versus the cost of an amphibious retrofit ranged from a low of 0.86 to a high of 19.9 , for an average ratio of 5.73 (Table 1). The base costs of constructing the amphibious retrofits used in these calculations range from a low of $\$ 108 / \mathrm{m}^{2}$ to a high of $\$ 432 / \mathrm{m}^{2}$.

The highlighted numbers (in red) in Table 1 illustrate the most likely building replacement cost versus flood mitigation cost scenarios. At a flood depth of $0.5 \mathrm{~m}$, the loss avoidance ratios range from 1.93 to 3.46 , and at a $1.5 \mathrm{~m}$ flood depth, these ratios range from 4.97 to 10.02 . These loss avoidance ratios demonstrate the financial advantages of implementing a buoyant foundation retrofit as a flood mitigation strategy.

\subsection{Wind Vulnerability}

Because wind speed increases with height above the surface of the earth, elevating a building will increase its vulnerability to wind damage (Fig. 23) [17]. Dr. John D. Holmes, an internationally prominent wind engineer based in Australia, conducted extensive studies of the damages sustained by elevated buildings in Australia's Gold Coast. He concluded that "the higher pressure coefficients on the elevated house are combined with a 
dynamic pressure based on the mean velocity at eaves height which is $20-30 \%$ higher. Thus the pressures occurring in the same windstorm may be expected to be $40-80 \%$ higher on the elevated building." [18]

Our recent study of the impact of wind loads on elevated buildings determined that an increase from $4 \mathrm{~m}$ to $10 \mathrm{~m}$ in the mean roof height of a home as a result of elevation creates a $75 \%$ increase in expected annual loss [19]. If a coastal community elevates their homes high above ground level to comply with FEMA regulations, these homes will be exposed to higher wind speeds, which carries an increased risk of roof damage (Fig. 24).

Amphibious buildings, as they remain close to the ground during windstorms unless there is a flood, do not experience the increased exposure to wind that is unavoidable for permanent static elevation.

\section{ICAADE}

In emerging fields such as amphibious construction, it is important to provide a forum to exchange knowledge between academics, practitioners, professionals and policy-makers, and to invite collaboration among researchers and institutions, companies, and governments around the world.

The first International Conference on Amphibious Architecture, Design and Engineering, ICAADE 2015, was held in Bangkok, Thailand, on August 26-29, 2015. The second conference, ICAADE 2017, will convene at the University of Waterloo in Ontario, Canada, June 2528, 2017 [20]. The conference will foster collaboration among architects, planners, builders, researchers, engineers and participants from government and industry, representing a broad range of disciplines such as water management, urban and landscape design, hydraulic engineering, social sciences, humanities, building construction, education and health, and experts from such fields as commerce, policy, information systems, and knowledge management.

\section{Conclusions}

Amphibious construction, though not a new concept, has been growing in popularity over the past decade. The implementation of buoyant foundations as both retrofit and new construction could provide benefit to communities at high risk of chronic flooding, from applications in New Orleans' Lower Ninth Ward to slums in Bangladesh, and elsewhere around the world.

This emerging technology allows for a floodmitigation strategy that is adaptable and cost-effective, and preserves community integrity. The Buoyant Foundation Project seeks to develop amphibious building practices and promote increased awareness of their potential to foster community resilience through retrofits to existing houses in flood-vulnerable areas around the world. Robust, sustainable strategies promoting passive resilience, such as amphibious architecture, encourage us to develop ways not just to live with water, but to thrive with it.

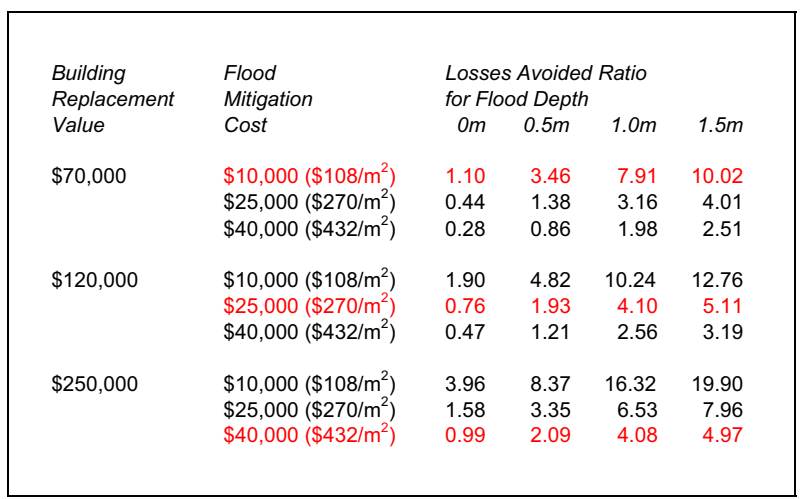

Table 1. Pinaymootang Loss Avoidance Summary

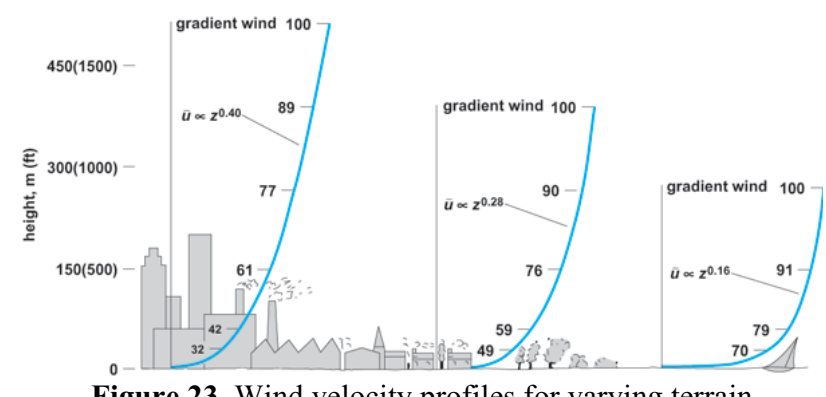

Figure 23. Wind velocity profiles for varying terrain roughnesses showing increased windspeeds with increased height above the ground (image courtesy English et al [19])

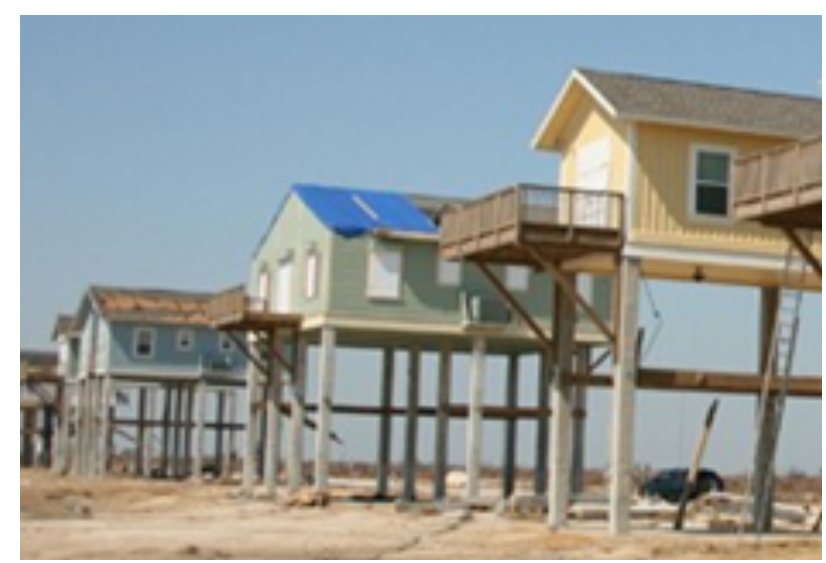

Figure 24. Wind-induced roof damage sustained by permanently statically elevated houses (image courtesy of the Journal of Light Construction)

\section{Acknowledgements}

This research was supported in part by grants from the International Development Research Centre and the Social Sciences and Humanities Research Council of Canada.

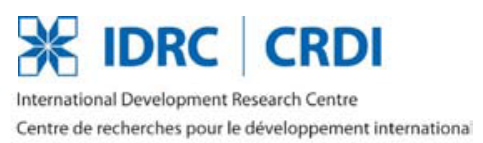

Social Sciences and Humanities Research Council of Canada

Conseil de recherches en sciences humaines du Canada

\section{Canadă}




\section{References}

1. United Nations Commission on Sustainable Development. (2007). Indicator Profile for Percentage of Total Population Living in Coastal Areas.

2. Kundzewicz, Z., Mata, L., Arnell, N., Döll, P., Kabat, P., Jiménez, B., Miller, K., Oki, T., Sen, Z. and Shiklomanov, I. (2007). Freshwater resources and their management. Climate Change 2007: Impacts, Adaptation and Vulnerability. Contribution of Working Group II to the Fourth Assessment Report of the Intergovernmental Panel on Climate Change, pp. 173-210.

3. Guha-Sapir, D., Below, R. and Hoyois, P. (2015). EM-DAT: The CRED/OFDA International Disaster Database. Université Catholique de Louvain, Brussels, Belgium. www.emdat.be

4. Liu, A., Fellowes, $M$ and Mabanta, M. (2006). Special edition of the Katrina Index: A one-year review of key indicators of recovery in post-storm New Orleans. Brookings Institution, Washington D.C., USA.

5. Buoyant Foundation Project, Inc. www.buoyantfoundation.org.

6. English, E. (2009). Amphibious foundations and the buoyant foundation project: Innovative strategies for flood resilient housing. Proceedings of the International Conference on Urban Flood Management, UNESCO-IHP and COST Action C22, Paris, France, 25 - 27 November 2009.

7. Federal Emergency Management Agency. (2007). Criteria for Land Management and Use: Requirements for Flood Plain Management Regulations. Federal Emergency Management Agency Regulations, 60.3, p. 4.

http://www.fema.gov/media-library-data/201307261622-20490-7844/section60_3.pdf

8. Fenuta, Elizabeth. (2010). Amphibious Architectures: The Buoyant Foundation Project in Post-Katrina New Orleans (Master of Architecture Thesis, University of Waterloo, Canada). Retrieved from https://www.uwspace.uwaterloo.ca/handle/10012/568

9. Prosun, Prithula. (2011). The LIFT House: an amphibious strategy for sustainable and affordable housing for urban poor in flood-prone Bangladesh (Master of Architecture Thesis, University of Waterloo, Canada). Retrieved from https: //www.uwspace.uwaterloo.ca/handle/10012/5787.

10. Hammond. G.P. and Jones, C.I. (2008). Embodied energy and carbon in construction materials. Proceedings of the Institution of Civil Engineers, Energy 161. Issue EN2, pgs. 87-98. doi: 10.1680/ener.2008.161.2.87

11. Turner, S. and English, E. (2015). Amphibious housing for vulnerable communities in Jamaica. Proceedings of the International Conference on Amphibious Architecture, Design and Engineering, Bangkok, Thailand, August 26 - 292015.

12. Davenport, C. and Robertson, C. (2016). "Resettling the First American "Climate Refugees"'. The New York Times. May 3, 2016. http://www.nytimes.com/ 2016/05/03/us/resettling-the-first-american-climaterefugees.html?emc $=$ edit_th_20160503\&nl=todayshea dlines\&nlid $=72460689 \& \_r=2$

13. Manitoba Infrastructure and Transportation (2013). 2011 Flood: Technical Review of Lake Manitoba, Lake St. Martin and Assiniboine River Water Levels.

14. Ropel-Morski, Z., English, E. and Turner, S. (2015). Amphibious Housing: An Innovative Approach to Seasonal Flood Mitigation for Vulnerable First Nations Communities. Proceedings of the International Conference on Amphibious Architecture, Design and Engineering, Bangkok, Thailand August 26 - 292015.

15. Bourdeau Jr, J. (2015). Loss Avoidance Studies. ASFPM Annual National Conference, Atlanta, USA, May 31 - June 52015.

16. Sumanth, S. and English, E. (2015). A loss avoidance study of amphibious housing: A case study in southern Louisiana. Proceedings of the International Conference on Amphibious Architecture, Design and Engineering, Bangkok, Thailand August 26-29 2015.

17. Cochran, L., ed., (2012). Wind issues in the design of buildings. American Society of Civil Engineers, Reston, Virginia.

18. Holmes, J. (1994). Wind pressures on tropical housing. Journal of Wind Engineering and Industrial Aerodynamics, 53(1-2), pp. 105-123.

19. English, E., Friedland, C., Orooji, F. and Mahtani, N. (2015). A new approach to combined flood and wind mitigation for hurricane damage prevention. Proceedings of the 14th International Conference on Wind Engineering, Porto Alegre, Brazil, June 21-26 2015 .

20. International Conference on Amphibious Architecture, Design and Engineering. (2016). ICAADE 2015. http://www.icaade.org 